\title{
PRINSIP KEADILAN ASASI DALAM UNDANG-UNDANG BERKAITAN PROSEDUR PERBICARAAN TATATERTIB DI JABATAN POLIS: SUATU ANALISA
}

\author{
Fariza Romli, Nuarrual Hilal Md Dahlan \& Rusniah Ahmad \\ Kolej Undang-Undang, Kerajaan dan Pengajian Antarabangsa \\ Universiti Utara Malaysia, Sintok, Kedah
}

\begin{abstract}
Abstrak
Prinsip keadilan asasi adalah merupakan syarat minima dalam membuat keputusan adil dan saksama yang dikenakan oleh undangundang terhadap orang atau badan bertugas khususnya yang bertindak secara kehakiman, termasuklah tribunal-tribunal dan juga mana-mana Lembaga Tatatertib Jabatan. Tiada sebarang definisi atau penjelasan yang khusus mengenai prinsip keadilan asasi di dalam mana-mana akta atau peraturan yang melibatkan prosedur tatatertib penjawat awam, tetapi prinsip ini diguna pakai dengan meluas dan merupakan syarat bagi menjamin prosedur perbicaraan adil dalam setiap perbicaraan. Pematuhan terhadap prinsip keadilan asasi ini amat penting dan sebarang perlanggaran boleh menyebabkan kes-kes tersebut boleh dirujuk di mahkamah untuk dibuat semakan semula atas keputusan yang diambil. Justeru, artikel ini akan melihat apakah peruntukan-peruntukan mengenai prinsip keadilan asasi yang terdapat di dalam undang-undang yang berkaitan dengan prosedur perbicaraan tatatertib di jabatan polis. Antara isu-isu yang dibincangkan ialah sejauhmana peruntukanperuntukkan tersebut terpakai dan juga mengenai kekangan dalam pelaksanaan prinsip tersebut. Metodologi yang digunakan adalah berdasarkan kajian perpustakaan berpandukan kepada analisa undang-undang terhadap akta-akta, peraturan-peraturan dan kes undang-undang yang terpakai ke atas Jabatan Polis. Diharap perbincangan dalam artikel ini dapat membantu memantapkan lagi undang-undang mengenai pengurusan tatatertib yang terpakai sekarang khususnya di jabatan polis bagi menjamin agar setiap pegawai yang dituduh berpeluang mendapat satu perbicaraan yang adil dan saksama.
\end{abstract}




\section{Pengenalan}

Pengurusan tatatertib dalam Perkhidmatan Awam amat penting bagi melahirkan pekerja yang berdisiplin, bermotivasi serta mengamalkan nilai-nilai murni dalam kehidupan. Ia juga dapat menjaga imej kerajaan dan juga imej Perkhidmatan Awam secara umum. Manamana pegawai awam yang didapati melanggar peraturan-peraturan yang berkaitan perlu mendapat hukuman. Tindakan tatatertib perlu diambil agar dapat memperbaiki tingkah laku mereka pada masa hadapan dan secara tidak langsung akan menjadi panduan kepada penjawat awam lain.

Pengurusan tatatertib adalah merupakan satu daripada mekanisme utama dalam pengurusan prestasi untuk meningkatkan mutu pengurusan sumber manusia sektor awam. Terdapat dua matlamat utama terhadap kawalan tatatertib, pertama untuk membentuk sikap yang positif dan mencegah daripada berlakunya penyelewengan dan matlamat kedua untuk melahirkan kakitangan yang bermotivasi dan

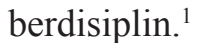

Semua pihak yang bertanggungjawab dalam mengendalikan sesuatu perbicaraan tatatertib termasuk kakitangan awam harus mengendalikannya dengan adil dan saksama. Keperluan berlaku adil ini amat penting kerana kebanyakan tindakan atau keputusan yang dibuat oleh pihak eksekutif boleh menjejaskan hak seseorang sama ada hak terhadap diri atau hartabenda. Kesan daripada hukuman yang dikenakan ada kalanya boleh menyebabkan penjawat awam terbabit kehilangan segala faedah serta hak seperti pencen, gratuiti, perubatan serta ganjaran cuti terkumpul yang sepatutnya diperoleh.

Dalam proses untuk berlaku adil ini, pihak yang bertanggungjawab mengenai urusan tatatertib bukan sahaja perlu mematuhi prosedurprosedur yang telah ditetapkan oleh statut, tetapi mereka juga perlu mematuhi prinsip keadilan asasi atau tabi'i (Rules of natural justice) yang merupakan salah satu prinsip penting dalam undang-undang pentadbiran.

1 Contoh Kes-Kes Tatatertib (Kuala Lumpur: Jabatan Perkhidmatan Awam,1992), 1 


\section{Pemahaman Mengenai Prinsip Keadilan Asasi}

Prinsip keadilan asasi merupakan satu konsep yang berkembang daripada sistem Common law Inggeris. Prinsip ini penting kerana menjadi asas di dalam membuat suatu keputusan yang adil dan saksama oleh mana-mana individu atau badan yang ditugaskan untuk bertindak secara kehakiman.

Professor De Smith menyebut:

"Peraturan keadilan asasi adalah taraf minimum dalam membuat keputusan yang saksama yang dikenakan oleh undang-undang terhadap orang atau badan yang bertugas yang bertindak secara kehakiman...isi kandungan keadilan asasi boleh berubah-ubah mengikut kesesuaiandanboleh berbeza-beza...,yang penting ialah kepentingan pihak yang terlibat perlu diambil kira". ${ }^{2}$

Seterusnya dalam kes $R$ lwn Sussex Justices ex parte Mc Carthyl, Hakim Lord Hewart pula menyebut:

"Adalah menjadi keperluan asas bahawa keadilan bukan sahaja dilaksanakan, tetapi perlu juga dipastikan yang ianya dilaksanakan".

Terdapat beberapa konsep penting mengenai pemakaian prinsip keadilan asasi dalam konteks pentadbiran seperti; jika sekiranya tindakan mana-mana pihak berkuasa boleh menjejaskan hak atau kepentingan atau jangkaan yang sah (legitimate expectation) seseorang, maka prinsip ini akan terpakai. Ia juga tidak membezakan sama ada kuasa membuat keputusan itu adalah kuasa kehakiman, kuasa separa kehakiman atau kuasa pentadbiran tulen. Hak untuk didengar ini diberikan juga walaupun mana-mana statut tiada peruntukan mengenainya. Kekosongan dan ketinggalan ini perlu dilengkapkan dengan Common Law, iaitu dalam konteks ini perlu diisi dengan prinsip keadilan asasi. Kenyatan ini seperti yang digambarkan dalam kes Cooper Iwn Wandworth Board of Works, ${ }^{4}$

2 De Smith, The Constititional and Administrative Law, Ed 5, (Harry Street dan Rodney Brazier(ed) Middlesex: Penguin Books, 1985)582

3 [1924] 1 KB 256.

4 [1863] 14 CBNS 180. 
"The justice of the common law will supply the omission of the legislature"

Di Malaysia, perkara ini disokong di dalam kenyataan Hakim Raja Azlan Shah dalam kes Ketua Pengarah Kastam lwn Ho Kwan Seng ${ }^{5}$, beliau memutuskan bahawa:

"the rule of natural justice that no man may be condemned unheard applies to every case where an individual is adversely affected by an administrative action, no matter whether it is labelled "judicial", quasi judicial" or "administrative' or whether or not the enabling statute makes provision for a hearing".

Konsep keadilan asasi ini perlu memenuhi dua prinsip utama iaitu:

- $\quad$ Prinsip audi alteram partem, iaitu orang yang dituduh diberi peluang yang mencukupi dan munasabah untuk menyatakan kesnya sewaktu perbicaraan diadakan.

- $\quad$ Prinsip 'tidak berat sebelah' (bias) atau nemo debet judex sua causa/nemo judex in causa sua potest.

\section{Prinsip Pertama- ‘audi alteram partem'.}

Prinsip pertama ini memberi peluang kepada orang yang dituduh untuk membela diri. Peluang untuk membela diri ini harus diberikan dengan sempurna dan mencukupi bagi memberi peluang pihak yang didakwa betul-betul bersedia untuk membuat pembelaan terhadap tuduhan yang dikenakan. Antara elemen-elemen di bawah prinsip audi alteram partem yang perlu dipatuhi bagi memastikan peluang pembelaan diberikan secara adil ialah:

a) Notis dakwaan tentang kesalahan atau dakwaan harus diberikan kepada tertuduh sebelum perbicaraan.

b) Masa yang munasabah diberikan kepada tertuduh untuk membuat representasi jawapan atau berhujah atas kesnya.

c) Hak untuk mengetahui dan mendapatkan semua maklumat atau keterangan yang akan digunakan semasa membuat keputusan.

d) Hak menyoal saksi.

5 [1977] 2 MLJ 152. 
e) Hak diwakili peguam.

f) Hak diberitahu keputusan dan dinyatakan keputusan.

g) Hak untuk merayu dan dengar semula.

Isi kandungan keadilan asasi boleh berubah-ubah mengikut kesesuaian dan boleh berbeza-beza, yang penting ialah kepentingan pihak terlibat perlu diambil kira dan dicapai tanpa berat sebelah dan selepas peluang yang secukupnya diberikan kepada pihak yang berkenaan untuk membentangkan kesnya. ${ }^{6}$

\section{Prinsip Kedua- Prinsip tidak Berat Sebelah (bias)}

Prinsip ini bererti seseorang yang ada kepentingan dalam sesuatu kes tidak boleh mengadili kes tersebut. Pihak yang mengadili kes seperti hakim dan penjawat awam yang mempunyai kuasa budibicara untuk membuat sesuatu keputusan perlulah bebas daripada membuat keputusan yang berat sebelah dan wujud prasangka. Keadaan terjadi disebabkan pihak-pihak tadi mempunyai kepentingan dan pihak yang mengadili sesuatu kes mewakili institusi yang menginginkan objektif tertentu atau pertalian tertentu atau sebagainya.

Menurut M.P Jain 7 , Prinsip tidak berat sebelah ini sebenarnya lahir daripada dua maxim iaitu:

a) Seseorang tidak boleh menjadi hakim dalam tindakannya sendiri. Maxim pertama ini terpakai bukan hanya kepada pihak hakim atau pengadil sendiri yang terlibat dalam kes-kes berkenaan, tetapi ianya memadai sekiranya hakim atau pengadil tadi ada kepentingan di dalam kes tersebut.

b) Keadilan bukan sahaja perlu dilakukan, malah perlu ditunjukkan bahawa ia berlaku.

Maxim kedua bermaksud, elemen berat sebelah (bias) wujud memadai sekiranya ada syak wasangka yang dapat diterima ramai tentang kredibiliti pihak hakim atau pihak yang akan membuat keputusan untuk berlaku adil.

6 Street $\mathrm{H}$ dan Brazier R. The Constitutional and Administrative Law, Edisi 5. (Middlesex: Penguin Books Ltd., 1985), 582.

7 Jain M.P., Administrative Law of Malaysia and Singapore, Edisi 4, (Lexis Nexis, 2011), 325. 
Proses kehakiman memerlukan seseorang hakim bertindak dengan adil dan saksama dengan menggunakan fikirannya sendiri secara objektif terhadap perkara yang perlu diputuskan dan secara umumnya prinsip tidak berat sebelah ini juga terpakai kepada manamana badan atau pihak yang diberi kuasa untuk membuat keputusan dalam pentadbiran perundangan (administrative adjudicatory).

\section{Pengurusan Kes Tatatertib di Jabatan Polis}

Punca kuasa yang membenarkan penubuhan Lembaga Tatatertib untuk pasukan polis termaktub di dalam Perkara 140(1)Perlembagaan Persekutuan Malaysia yang menyebut:

"Maka hendaklah ada suatu Suruhanjaya Pasukan Polis dan bidangkuasanya hendaklah meliputi semua orang yang menjadi anggota pasukan polis dan, tertakluk kepada peruntukan mana-mana undang-undang yang ada, Suruhanjaya itu hendaklah bertanggungjawab bagi melantik, mengesahkan, memasukkan ke dalam perjawatan tetap atau perjawatan berpencen, kenaikan pangkat, pertukaran dan menjalankan kawalan tatatertib ke atas anggota pasukan polis: dengan syarat bahawa Parlimen boleh dengan undang-undang mengadakan peruntukan mengenai perjalanan apa-apa kawalan tatatertib ke atas semua atau mana-mana daripada anggota-anggota pasukan polis mengikut apa-apa cara dan oleh mana-mana pihak berkuasa sebagaimana yang diperuntukkan dalam undang-undang itu...".

Berdasarkan peruntukan di atas, tidak semua tugas dan tanggungjawab tersebut dilaksanakan oleh Suruhanjaya kerana sebahagian daripada tugas-tugas kewajipan dan tanggungjawab tersebut diwakilkan kuasa kepada Ketua Polis Negara dan Pegawaipegawai Kanan Polis termasuklah dalam kes tatatertib.

Selain Perlembagaan Persekutuan sendiri yang menjadi sebagai undang-undang tertinggi negara, peraturan-peraturan lain yang menjadi rujukan utama melibatkan pengurusan tatatertib polis ialah Peraturan-Peraturan Pegawai Awam (Kelakuan dan Tatatertib) $1993^{8}$

$8 \quad$ [P.U.(A) 395] \& Pindaan 2002, [P.U.(A) 246]. 
dan Suratcara Perwakilan Fungsi-Fungsi, Kuasa-Kuasa, TugasTugas Dan Tanggungjawab-Tanggungjawab tertentu. ${ }^{9}$

Laporan yang diperoleh daripada Biro Bantuan Guaman (BBG) mendapati statistik aduan yang diterima dari tahun 2007 sehingga 30 April 2010 menunjukkan Polis di Raja Malaysia (PDRM) terletak di tangga teratas di kalangan 10 agensi Kerajaan Persekutuan yang menerima aduan tertinggi bagi tempoh 1 Januari sehingga 30 April 2010. Institut Integriti Malaysia (IIM) dalam laporan mereka telah merujuk kepada tindakan tatatertib yang telah diambil sebagai indikator untuk melihat kualiti penyampaian perkhidmatan awam kerana lebih ramai kakitangan awam yang dikenakan tindakan tatatertib bermakna wujud masalah disiplin dan integriti yang serius dalam kalangan penjawat awam. Bagi Polis di Raja Malaysia sendiri, maklumat perangkaan tindakan tatatertib mengikut pelbagai kesalahan dari tahun 2001 sehingga Mac 2008 adalah sebanyak 6737 kes dan daripada jumlah tersebut perangkaan hukuman tatatertib untuk kes turun pangkat dan buang kerja sahaja adalah sebanyak 500 kes.

Bagi menangani kes-kes tatertib seperti di atas, khususnya kes turun pangkat dan buang kerja, satu prosedur yang mantap dan berkesan amatlah perlu agar proses perbicaraan berjalan dengan lancar, selain keanggotaan ahli dalam lembaga tatatertib sendiri yang memerlukan seseorang yang berwibawa dalam urusan tatatertib.

\section{Prinsip Keadilan Asasi di dalam Undang-Undang dan Peraturan-Peraturan yang Berkaitan}

Dalam menguruskan kes-kes tatatertib yang melibatkan pasukan polis, terdapat tiga undang-undang utama yang dibincangkan di sini melibatkan pasukan polis. Pertama, Perlembagaan Persekutuan Malaysia sendiri yang merupakan undang-undang paling tinggi dan utama kerana terdapat peruntukan yang memelihara hak penjawat awam. Kedua, Peraturan-Peraturan Tatatertib Pegawai Awam (Kelakuan dan Tatatertib) 1993 dan yang ketiga, P.U (B) 441Suratcara Perwakilan Fungsi-Fungsi, Kuasa-Kuasa Tugas-Tugas Dan Tanggungjawab-Tanggungjawab Tertentu.

$9 \quad$ [P.U (B) 441] bertarikh 14.12.2000 


\section{Perlembagaan Persekutuan Malaysia}

Perlembagaan Persekutuan Malaysia mempunyai peruntukan tentang keadilan asasi apabila memasukkan elemen 'peluang yang munasabah untuk didengar' di dalam Perkara 135(2). Antara lain ia memperuntukkan bahawa tiada seseorang anggota mana-mana perkhidmatan awam boleh dibuang kerja atau diturunkan pangkat dengan tidak diberi peluang yang munasabah untuk didengar. ${ }^{10} \mathrm{Fasal}$ di atas bermaksud untuk memberi perlindungan kepada pegawaipegawai dalam perkhidmatan awam daripada sebarang tindakan arbitrari (arbitrary power) oleh kerajaan, seperti penurunan pangkat dan pemecatan jawatan.

Perkara 135 memberi pelindungan serta kawalan kepada semua penjawat awam, termasuk anggota polis ${ }^{11}$ agar tindakan pembuangan kerja atau penurunan pangkat tidak dilakukan dengan sesuka hati. Perkara ini telah dinyatakan juga oleh Majlis Privy dalam kes Mahan Singh Iwn Kerajaan Malaysia ${ }^{12}$. Hakim Lord Diplock menyatakan:

"Secara prima facie, Yang Di Pertuan Agong boleh menamatkan perkhidmatan mana-mana penjawat awam tanpa notis dan pada masa yang Baginda suka; tetapi hak ini tertakluk kepada Perkara 135(2) Perlembagaan iaitu penjawat awam tidak boleh dibuang kerja tanpa diberi hak didengari kesnya".

Perkataan "peluang yang munasabah untuk didengar" dalam Perkara 135 Fasal (2) adalah hak yang diasaskan di bawah prinsip Common Law iaitu prinsip 'audi alteram partem' yang merupakan prinsip pertama dibawah konsep keadilan asasi atau 'natural justice'. Kewujudan prinsip ini didalam Perkara 135(2) Perlembagaan Persekutuan telah menukar "hak atau peluang yang munasabah untuk didengar" kepada hak di bawah Perlembagaan (constitutional right $)^{13}$ dengan mendapat perlindungan terus dari Perlembagaan Persekutuan yang merupakan undang-undang tertinggi negara.

10 Perintah Am Bab 'D'.

11 Rujuk Perkara 132 Perlembagaan Persekutuan.

12 [1978] 2 MLJ 133, hlm.135

13 Zulkifli Ahmad Makinudin, "Disciplinary Proceedings Against Public Officers And The Right To Be Heard Under The Federal Constitution Of Malaysia," Current Law Journal. CLJ 5 (2012): iv. 


\section{Peraturan-Peraturan Tatatertib Pegawai Awam (Kelakuan dan Tatatertib) 1993}

Peraturan-Peraturan Pegawai Awam (Kelakuan dan Tatatertib) 1993, Bab D merupakan dokumen perundangan utama yang menjadi rujukan agensi kerajaan, termasuklah pasukan polis untuk memastikan perlakuan tatatertib kakitangannya terkawal. Ia juga menjadi panduan dalam mengenakan tindakan tatatertib bagi penjawat awam yang melanggar peruntukan di dalamnya.

Peraturan 34(1) Bahagian V, Perintah Am Bab D juga telah memasukkan elemen 'peluang yang munasabah untuk didengar', selari dengan peruntukan yang terdapat di dalam Perkara 135(2) Perlembagaan Persekutuan tertakluk kepada beberapa pengecualian seperti yang tersebut di dalam peruntukan berkenaan. ${ }^{14}$

Peraturan tersebut melibatkan prosedur tatatertib dan menyatakan seperti berikut:

"Tertakluk kepada subperaturan (2), tiada seorang pegawai pun boleh dibuang kerja atau diturunkan pangkat dalam apa-apa prosiding tatatertib di bawah Bahagian ini, melainkan jika pegawai itu telah terlebih dahulu diberitahu secara bertulis mengenai alasanalasan yang berdasarkannya tindakan itu dicadangkan dan pegawai itu telah diberi peluang yang munasabah untuk didengar".

Prosedur di bawah Perintah Am Bab D ini terbahagi kepada dua; iaitu (i) pertama tatacara bagi kes yang melibatkan hukuman bukan dengan buang kerja atau turun pangkat dan (ii) kedua tatacara bagi kes yang melibatkan hukuman buang kerja atau turun pangkat.

Terdapat beberapa elemen keadilan asasi yang diserap di dalam prosedur ini seperti pemberian notis dan juga tempoh masa yang sesuai untuk membuat representasi. Sekiranya wujud suatu kesalahan tatatertib, pegawai perlu dimaklumkan melalui notis di bawah Peraturan 52 (kesalahan selain dari buang kerja atau turun pangkat) mengenai fakta kesalahan tatatertib yang dikatakan telah

14 Perkara 135(2) (a)-(d). 
dilakukan olehnya dan hendaklah memberi pegawai itu peluang untuk membuat representasi bertulis dalam tempoh 21 hari dari tarikh dia dimaklumkan mengenai fakta tersebut. Setelah Pihak Berkuasa Tatatertib menimbangkan representasi pegawai termasuk penjelasan lanjut sekiranya ada dan mendapati pegawai itu bersalah, maka pegawai itu akan dikenakan mana-mana satu atau lebih hukuman sebagaimana yang difikirkan sesuai. Pegawai akan dibebaskan sekiranya didapati tidak bersalah.

Di bawah Peraturan 37 pula (kesalahan dengan tujuan buang kerja atau turun pangkat) jika wujud suatu kes prima facie terhadap pegawai itu, pegawai berkenaan diberi tempoh selama 21 hari dari tarikh dia dimaklumkan pertuduhan itu melalui notis di bawah peraturan 52 untuk menghantar suatu representasi bertulis yang mengandungi alasan-alasan untuk membela diri. Pegawai akan ditentukan sama ada bebas dari tuduhan atau tidak hanya berdasarkan representasi bertulis yang telah diserahkan.

Sekiranya Pihak Berkuasa tatatertib yang berkenaan berpendapat bahawa kes terhadap pegawai itu menghendaki penjelasan lanjut, Pihak Berkuasa tatatertib boleh menubuhkan suatu Jawatankuasa Penyiasatan untuk mendapatkan maklumat dan penjelasan lanjut mengenai kes berkenaan. Jawatankuasa Penyiasat boleh memanggil dan memeriksa mana-mana saksi atau mengambil apa-apa tindakan yang difikirkan patut untuk mendapatkan penjelasan lanjut mengenai kes ini. Peraturan 37(B) (2) membenarkan pembelaan secara lisan di adakan di peringkat penyiasatan.

Dalam proses siasatan ini, jika saksi-saksi juga dipanggil dan diperiksa oleh Jawatankuasa Penyiasatan, pegawai itu juga hendaklah diberi peluang untuk hadir dan untuk menyoal balas saksi-saksi bagi pihak dirinya. ${ }^{15}$ Keterangan dokumentari atau 'documentary evidence' tidak boleh digunakan terhadap seseorang pegawai melainkan jika sebelum ini pegawai itu telah dibekalkan dengan satu salinan keterangan yang sama atau telah diberi akses kepada keterangan itu. ${ }^{16}$

15 Peraturan 37B(3)- Peraturan-Peraturan Pegawai Awam (Kelakuan dan tatatertib) 1993.

16 Peraturan 37B(4). 
Seterusnya jawatankuasa Penyiasat boleh membenarkan Kerajaan atau pegawai itu diwakili oleh seorang pegawai perkhidmatan awam atau, dalam hal yang luar biasa oleh seorang peguam bela dan peguam cara, tetapi Jawatankuasa Penyiasatan boleh menarik balik kebenaran itu tertakluk kepada apa-apa penangguhan yang munasabah dan perlu bagi membolehkan pegawai itu untuk membentangkan kesnya sendiri. ${ }^{17}$

Berdasarkan penjelasan mengenai peruntukan-peruntukan yang terdapat di dalam Peraturan-Peraturan Tatatertib Pegawai Awam (Kelakuan \& Tatatertib) 1993, penulis mendapati prinsip keadilan asasi hadir secara tersirat kerana hanya elemen-elemen di dalam prinsip tersebut dimasukkan di dalam peruntukan undang-undang yang dibincangkan di atas. Sebagai contoh, elemen notis, peluang yang munasabah untuk didengar serta hak diwakili oleh pegawai dalam perkhidmatan awam atau diwakili peguam.

\section{P.U (B) 441- Suratcara Perwakilan Fungsi-Fungsi, Kuasa-Kuasa Tugas-Tugas dan Tanggungjawab-Tanggungjawab Tertentu}

Warta Kerajaan P.U (B) 441 bertarikh 14.12.2000 adalah melibatkan penurunan kuasa, keanggotaan lembaga tatatertib, fungsi dan bidang kuasa masing-masing serta hal-hal lain yang ada perkaitan dengan tatatertib untuk Pasukan polis.

Kebanyakan kes adalah melibatkan Kumpulan Pegawai Rendah Polis dan Konstabel. Dalam kes buang kerja dan turun pangkat yang melibatkan pegawai di atas, Ahli Lembaga Tatatertib boleh dari kalangan Penolong Pesuruhjaya Polis hingga ke Jawatan Ketua Polis Negara sebagai Pengerusi Lembaga Tatatertib serta 2 orang ahli yang tidak kurang dari pangkat Penolong Penguasa Polis. Kebiasaannya, kes-kes tatatertib bagi kumpulan ini akan dikendalikan oleh Jabatan Polis di negeri masing-masing dan di anggotai oleh Lembaga Tatatertib yang disyaratkan di atas.

Di bawah P.U. (B) 441/2000 yang terpakai sekarang, Lembaga Tatatertib perlu mempunyai 3 korum untuk mendengar perbicaraan mana-mana pegawai polis yang didapati bersalah dan melanggar undang-undang. Keadaan ini adalah lebih baik berbanding dengan

17 Peraturan 37B(5). 
perbicaraan yang dilaksanakan sebelum ini, di bawah P.U (B) 621 yang dikenali sebagai Acara Kamar yang hanya mensyaratkan satu keanggotaan sahaja.

Prinsip tidak berat sebelah atau prasangka (bias) boleh berlaku dalam keadaan tertentu berdasarkan jadual keanggotaan lembaga tatatertib yang terpakai sekarang di mana pihak yang membuat aduan kesalahan tatatertib akhirnya atau berkemungkinan menjadi ahli dalam lembaga tatatertib sendiri. Sebagai contoh, jika Ketua Polis Daerah berpangkat penguasa, mengadu mengenai kesalahan tatatertib, selepas siasatan dan di dapati wujud kes 'prima facie', akhirnya Ketua Polis daerah yang sama juga menjadi salah seorang ahli dalam Lembaga Tatatertib berkenaan. Situasi ini adalah bertentangan dengan konsep tidak berat sebelah atau 'rules against bias' kerana konsep ini mensyaratkan agar pihak-pihak yang mengendalikan tindakan tatatertib tidak boleh mempunyai sebarang kepentingan semasa membuat keputusan. Dalam kes Cooper lwn Wilson [1937] 2 KB 309, di mana seorang pegawai polis dipecat oleh ketua polis dan ketika kes rayuan didengar, ketua polis tersebut turut hadir sebagai pemerhati. Mahkamah memutuskan kehadiran ketua polis menyebabkan kemungkinan berlakunya prasangka bias. Begitu juga dalam kes Chong Kok Lim lwn Yong Su Hian ${ }^{18}$ di mana mahkamah memutuskan bahawa keputusan pemecatan responden adalah tidak sah kerana orang yang membuat tuduhan menjadi pengerusi dalam mesyuarat Agong persatuan yang mengesahkan pemecatan tersebut. Untuk mengelak daripada berlakunya sebarang elemen pilih kasih dalam apa situasi sekalipun atau apabila pihak yang membuat aduan terlibat sama sebagai ahli lembaga tatatertib, adalah lebih elok sekiranya dimasukkan di dalam peruntukan undang-undang yang mesyaratkan sekiranya dirasakan akan wujud elemen berat sebelah, maka pegawai berkenaan patut digantikan dengan orang lain yang mempunyai pangkat yang sama atau lebih tinggi daripada beliau.

Selain prinsip berat sebelah atau prasangka (bias) yang boleh wujud dalam beberapa situasi seperti yang dibincangkan di atas, P.U (B) 441 juga tiada peruntukan yang membenarkan mana-mana pegawai yang telah didapati bersalah dan dijatuhkan hukuman untuk membuat rayuan ke peringkat yang lebih tinggi dalam Jabatan berkenaan. Mereka harus menerima keputusan yang telah diputuskan

18 [1979] 2 MLJ 11. 
dan sekiranya tidak berpuas hati dengan keputusan tersebut, mereka hanya boleh membuat semakan semula di Mahkamah Tinggi. Ketiadaan ruang untuk membuat rayuan diperingkat jabatan boleh menyekat hak seseorang untuk mendapatkan keadilan. Walaupun ruang diberi untuk membuat semakan semula di Mahkamah Tinggi seperti dalam Aturan 53, Kaedah-Kaedah Mahkamah 2012, penulis merasakan tidak ramai yang akan berbuat demikian lebih-lebih lagi bagi pegawai rendah polis atas faktor kewangan dan kurang pendedahan serta pengetahuan tentang hak yang mereka ada.

\section{Kekangan Pelaksanaan Prinsip Keadilan Asasi}

Maksud 'peluang yang munasabah untuk didengar' di dalam Perlembagaan dan undang-undang lain yang berkaitan tidak diberi sebarang penjelasan atau tafsiran lanjut. Situasi ini menyukarkan pihak lembaga tatatertib, urusetia serta mana-mana pihak yang berkepentingan untuk memahami maksud dan mengaplikasikannya kerana tiada skop yang jelas dan tepat diberikan. Keadaan ini mungkin menjadi lebih sukar sekiranya pihak-pihak berkuasa tersebut tidak mempunyai latarbelakang undang-undang. Justeru wujud pelbagai interpretasi yang diberikan oleh mahkamah dalam menentukan skop dan tafsiran maksud ayat di atas sebagai contoh timbul isu adakah memadai pembelaan dibuat secara bertulis dan menafikan perbicaraan secara lisan serta isu untuk diwakili oleh peguam. Situasi seperti ini dapat dilihat dalam beberapa kes seperti kes Ang Seng Wan Iwn Suruhanjaya Polis Di Raja Malaysia \& Anor, ${ }^{19}$ Mat Ghaffar Baba Iwn Ketua Polis Negara \& Anor ${ }^{20}$ dan

19 [2002] 1 CLJ 493, Mahkamah Rayuan memutuskan, memandangkan bahawa tidak terdapat keterangan untuk menyangkal kenyataan-kenyataan plaintif yang membebaskannya daripada tuduhan dan laporan-laporan yang biasa dan kenyataan saksi-saksi telah tidak dibekalkan kepada plaintif, Suruhanjaya sepatutnya mengadakan satu perbicaraan lisan atau siasatan. Kegagalan Suruhanjaya tersebut untuk mengadakan satu perbicaraan lisan telah melucutkan hak plaintif dari peluang untuk didengar dengan sewajarnya. Akibatnya prosiding tatatertib yang dikendalikan oleh Suruhanjaya tersebut adalah tidak konsisten dengan kaedah-kaedah keadilan asasi seperti yang termaktub dalam Perkara 135(2) Perlembagaan Persekutuan.

20 [2008] 1 CLJ halaman??? Di dalam kes ini plaintif telah dibuang kerja dari pasukan polis tanpa diberi pendengaran lisan walaupun telah dipohon oleh plaintif, mahkamah memutuskan bahawa pihakberkuasa disiplin gagal menimbang tuduhan-tuduhan yang dibuat terhadap plaintif dan menentukan sama ada pendengaran lisan diperlukan memandangkan kes plaintif rumit dan tidak memadai jika pembelaan hanya dibuat secara bertulis. Perintah 
kes Ghazi bin Mohd Sawi lwn Mohd Haniff bin Omar, Ketua Polis Negara Malaysia \& Anor. ${ }^{21}$

Hak membela diri penjawat awam khususnya yang melibatkan prinsip keadilan asasi banyak terdapat semasa proses penyiasatan dibuat. Akan tetapi proses penyiasatan ini tidak terpakai dalam semua kes. Ianya terletak atas budibicara Jawatankuasa Tatatertib yang berkenaan untuk menentukan sama ada perlu ditubuhkan Jawatankuasa Penyiasatan atau tidak. Keadaan ini seolah-olah menyekat suatu proses perbicaraan yang adil daripada terpakai oleh semua penjawat awam sedangkan hak untuk didengar sendiri dijamin di dalam Perlembagaan Persekutuan supaya diaplikasikan sebelum seseorang penjawat awam dibuang kerja atau diturunkan pangkat.

Pegawai akan ditentukan sama ada bebas daripada tuduhan atau tidak hanya berdasarkan representasi bertulis yang telah diserahkan. Sekiranya sesuatu kes perlu kepada penjelasan lanjut secara lisan, ia menjadi agak sukar dilaksanakan kerana tiada peruntukan yang jelas mengenai perbicaraan secara lisan di dalam peraturan-peraturan penjawat awam yang terpakai kini walaupun menurut prinsip asas keadilan asasi membenarkan perbicaraan secara lisan di adakan di dalam kes-kes tertentu.

Hakim dalam kes Raja Abdul Malik ${ }^{22}$ menyatakan bahawa:

"...hak untuk didengar tidak dalam kesemua keskes termasuk hak untuk diberikan perbicaraan lisan. Walaubagaimanapun, ia tidak bererti bahawa kegagalan atau keengganan untuk memberikan perbicaraan berkenaan tidak boleh dicabar".

pembuangan kerja diketepikan oleh mahkamah. Plaintif diperintah diambil bekerja kembali dan akan diberi semula gaji, emolument dan faedah-faedah yang terakru kepada plaintif.

21 [1994] 2 CLJ halaman???dalam kes ini mahkamah menyebut bahawa terma "peluang untuk didengar' atau "hak untuk didengar", dalam konteks peraturan keadilan asasi, tidak bermaksud sebarang tanggungjawab untuk mengadakan penyiasatan dan begitu juga perkataan "pendengaran" tidak bermakna "pendengaran lisan". Apa yang penting, pegawai yang berkenaan seharusnya mempunyai peluang yang penuh bagi mengemukakan kesnya sebelum beliau disingkirkan.

22 Raja Abdul Malek Muzaffar Shah bin Raja Shahruzzaman Iwn Setiausaha Suruhanjaya Pasukan Polis \& Ors [1995] 1 MLJ 308. 
Peluang membuat representasi juga diberikan, tetapi terdapat perbezaan yang ketara antara representasi yang dibuat oleh Pegawai Kanan Polis dengan representasi yang dibuat oleh pegawai berpangkat rendah. Didapati representasi oleh pegawai atasan lebih mantap isu kandungan pembelaannya berbanding representasi oleh pegawai bawahan yang amat lemah. Justeru amat penting pegawai yang dituduh memahami tujuan dan kesan representasi yang dibuat. Situasi seperti ini terjadi mungkin mempunyai perkaitan dengan tahap pendidikan atau disebabkan ketidakfahaman pegawai rendah polis terhadap proses yang kurang diberi penjelasan oleh pihak jabatan.

Di bawah P.U(B) 441/2000 sendiri, tiada peruntukkan untuk pegawai membuat rayuan setelah keputusan dibuat. Pegawai yang tidak berpuashati di atas hukuman yang dijatuhkan khususnya yang telah diturunkan pangkat atau dibuang kerja tidak berpeluang untuk membuat sebarang rayuan ke peringkat yang lebih tinggi. Manamana pihak yang tidak berpuas hati dengan keputusan Lembaga Tatatertib harus membuat permohonan terus di Mahkamah Tinggi.

\section{Kesimpulan}

Pemantapan dan peningkatan sistem pengurusan tatatertib hanya akan diperoleh jika sekiranya semua pihak yang terlibat memberi sepenuh kepercayaan dan keyakinan bahawa badan yang ditugaskan melaksanakan fungsi tersebut sentiasa mematuhi prosedur yang ditetapkan dan bertindak dengan penuh tanggungjawab dan adil. Pihak-pihak yang diberi kuasa untuk membuat keputusan harus melaksanakan kuasa budibicara yang diberi dengan jujur dan benar dengan menghormati hak-hak tertuduh dan menjatuhkan hukuman bersesuian dengan kesalahan.

Daripada aspek peraturan-peraturan yang terpakai kepada pasukan polis, didapati pelaksanaan prinsip keadilan asasi adalah tidak menyeluruh kerana beberapa elemen dalam prinsip keadilan asasi seperti pembelaan secara lisan, hak diwakili peguam juga hak menyoal saksi hanya terpakai sekiranya lembaga tatatertib memutuskan agar penyiasatan lanjut diadakan. Hakikatnya, tidak semua kes tertakluk kepada penyiasatan lanjut kerana ia hanya diberi tertakluk kepada budibicara lembaga tatatertib sekiranya dirasakan perlu. 
Di bawah P.U (B) 441/2000, tiada sebarang peruntukan bagi membolehkan pihak yang telah dijatuhkan hukuman membuat rayuan sekiranya tidak berpuas hati dengan keputusan tersebut. Ketiadaan peluang untuk membuat rayuan di peringkat jabatan menunjukkan satu lagi elemen prinsip keadilan asasi telah diketepikan. Jika masih tidak berpuas hati, pihak yang terjejas tadi harus membawa kes mereka terus ke Mahkamah Tinggi untuk dibuat semakan.

Dalam usaha untuk memartabatkan perkhidmatan awam negara bertaraf dunia dalam menghadapi pelbagai cabaran di alaf moden ini, isu-isu berkaitan tatatertib dalam perkhidmatan awam harus diberi perhatian dan penekanan yang serius. Ini kerana ketidakpuasan hati rakyat akan jelas tergambar sekiranya kes-kes yang melibatkan tatatertib penjawat awam banyak dibawa ke mahkamah untuk dibuat semakan khususnya atas sebab kegagalan mematuhi prosedur yang ditetapkan. Justeru, segala permasalahan yang boleh menyebabkan prinsip keadilan asasi tidak dapat dilaksanakan dengan sempurna harus ditangani dengan segera supaya penambahbaikan dapat dibuat bagi memantapkan lagi prosedur tatatertib selain menjamin agar setiap pegawai yang dituduh mendapat satu perbicaraan yang adil dan saksama.

\section{Bibliografi}

Abdul Aziz Hussin, Undang-Undang yang mengenai kelakuan dan Tatatertib Penjawat Awam: Hak dan Tanggungjawab, Kuala Lumpur:Dewan Bahasa Dan Pustaka,1994.

Abdul Aziz Bari, Armed Forces Personnel As Public Servants Under The Federal Constitution: A review on the decision in Abdul Salam bin Husin, Malayan Law Journal 1 (2001):xxix.

Abdul Aziz Bari, Termination Of Service In The Public Interest And The Right To Be Heard Under The Federal Constitution, International Islamic University Malaysia Law Journal, IIUMLJ 10 (2002):105.

Anwarul Yaqin \& Nik Ahmad kamal, The Public Servant's Right To Plead Mitigation In Disciplinary Proceeding: Some Reflections On The Recent Federal Court Judgment In Utra Badi, Malayan Law Journal MLJ 4 (2001): xlix. 
A.V Dicey, An Introduction to the Study of the Law of the Constitution, Edisi 10, London: Macmillan Education Ltd. (1987):xxxiii.

Anwarul Yakin \& Nik Ahmad Kamal, Review and Appellate Powers: An Elusive Quest For maintaining The Dividing Line, Malayan Law Journal 3 (2004):lxvi.

C.C. Gan, Disciplinary Proceedings Against Public Officers in Malaysia. Singapore:Lexis Nexis, 2007.

C.C.Gan, Disciplinary Proceedings Against Public Officers - An Update On Recent Legislation And Case Law , Current Law Journal CLJ 2 (1996):lxxxix

C.C. Gan, Administrative Law: An Update, Current Law Journal, CLJ 3(1991):li

C.C. Gan, The function and powers of the Public Services Commission: An Analysis Of The Rights Of Public Servant as Protected by the Constitution and Common Law.Thesis (Ph.D) Universiti Malaya, 1999.

Choudhry, T.G, Penumbra Of Natural Justice, Edisi 2, Culcutta/ New Delhi:Eastern Law House, 2001.

C.V Das, Administrative Law And The Citizen, Current Law Journal (Part II), CLJ 1(1981):114

De Smith, The Constitutional and Administrative Law, Edisi 5. Harry Sheet dan Rodney Brazier (ed) Middlesex: penguin Books ltd. 1985.

De Smith,Woolf \& Jowell, Judicial Review Of Administrative Action, United Kingdom:Sweet \& Maxwell Ltd. 1995.

Fordham,M., Judicial Review Handbook, Great Britain:Bookcraft ltd. 1995.

Geoggrey A Flick, Natural Justice: Principles and Practical Application, Butterworth, 1979. 
Hari Chand, Malaysia Administrative Law: Has It Come Of Age, Malaysian Journal Of Law Society, MJLS 2 (1998):1-22.

Hairuddin, Hak Untuk Didengar, Current Law Journal, CLJ 1(1992): XXXV

Contoh Kes-kes Tatatertib, Jabatan Perkhidmatan Awam Malaysia. Kuala Lumpur: Jabatan Percetakan Negara.[1992].

Kes-Kes Tatatertib Yang di Bawa ke Mahkamah, Jabatan Perkhidmatan Awam Malaysia, Kuala Lumpur: Jabatan Percetakan Negara.[1992].

Kamal Halili Hasan, Cabaran Perundangan Dalam Hubungan Majikan-Pekerja Sektor Awam dan Swasta, Bangi: Penerbit Universiti Kebangsaan Malaysia, 2008.

M.P Jain, Administrative Law of Malaysia and Singapore, Edisi 4, Kuala Lumpur: Malayan Law Journal, 2011.

M.P Jain, Administrative Law in Malaysia dlm. Malaysian Legal Essays. M.B Hooker (ed) Kuala Lumpur : Malayan Law Journal, 1980.

Nik Ahmad kamal, Perkhidmatan Awam dlm.Perkembangan Undang-Undang Perlembagaan Persekutuan (ed) Ahmad Ibrahim, Kuala Lumpur: Dewan Bahasa Dan Pustaka, 1999.

Phillips O. H. \& Jackson, P. Constitutional and Administrative Law, Edisi 8, London: Sweet \& Maxwell, 2001.

P.Paul Craig , Administrative Law, Edisi 1, London: Sweet \& Maxwell 1td. 1983.

Sudha, The Changing Faces of Administrative Law in Malaysia, Malayan law Journal, MLJ 1 (1999):cxl.

V Ananta Raman, Natural Justice- The Malaysian Experience, Malayan Law Journal, MLJ 3 (1993):i. 
V.S. Winslow, Public Service and Public Servants in Malaysia dlm Tun Muhd Suffian, H.P.Lee dan F.A Trinidade (ed) 1979 dan The Constitution Of Malaysia: Its Development: 1957-1977. Edisi Pertama. Kuala Lumpur: Oxford University Press, m/s 265,1979 .

Wade H.R, Administrative Law, Edisi 6, University Printing House, Oxford, 1988.

Zulkefli Ahmad Makinudin, Disciplinary Proceedings Against Public Officers And The Right To Be Heard Under The Federal Constitution Of Malaysia, Current Law Journal, CLJ 5 (2012): i-viii.

\author{
Akta/ Statut \\ Perlembagaan Persekutuan Malaysia \\ Peraturan-Peraturan Pegawai Awam ( Kelakuan dan Tatatertib) \\ 1993.
}

P.U/(B) 441/2000 - Suratcara Perwakilan Fungsi-Fungsi, Kuasa-Kuasa Tugas-Tugas Dan Tanggungjawab-Tanggungjawab Tertentu. 